\title{
Dynamic Response Analysis of Long-span Continuous Bridge under Earthquake and Train Loads \\ Xing-Jun GAO ${ }^{1, a,{ }^{*}}$, Kun WANG ${ }^{2, b}$, Ming-Yu LI, ${ }^{1, c}$
}

\author{
${ }^{1}$ School of Civil Engineering, Zhengzhou University, Zhengzhou, 450001, Henan Province, China \\ ${ }^{2}$ Er Chu Co., Ltd. of China Railway Tunnel Group,Tangshan, 065201, Hebei Province, China \\ agxjun@zzu.edu.cn, b148094081@qq.com, c150302137@qq.com
}

${ }^{*}$ Corresponding author

Keywords:Inclined Seismic Wave, Vehicle-Bridge Interaction, Soil Foundation, Dynamic Analysis, Soil-Structure Dynamic Interaction.

\begin{abstract}
In this paper, the dynamic response analysis of long-span continuous bridge under earthquakes and train loadsimultaneously were performed. In order to considerthe coupled vibrations of vehicles and highway long-span continuous bridge, a numerical modelinvolving soil foundation under inclined seismic wave was established using finite element software. The dynamic response ofthe bridge withdifferentincidenceangles of seismic waves and the differenttrain speedswere calculated and analyzed.The results show that seismic waveincident angles have a significant effect on the dynamic responseof the bridge, and with the increasing of the incident angle, thevertical displacements, velocity and accelerations of mid-spanconstantly increase. While thetrain speeds have a slightly effect on the dynamic responseof the bridge under earthquake, and the dynamic responseof the bridge reach maximum at a certain speed.
\end{abstract}

\section{Introduction}

The events of train derailment which once have happened under earthquake load did not cause enough attention in early time because the train speed was low and the railway bridge was relatively short[1]. The main focus was bridge seismic problems in railway engineering at that time, so the contribution of running trains for seismic response of the bridge was generally not considered.

With the rapid construction of high-speed railway, the proportion of the bridge in the railway was more and more large and the maximum reached to $70 \%$ in order to ensure the comfort and stability of the railway line[2], as a result, the probability that the train was running on the bridge when the earthquake happens would increase largely, and the problem of vehicle-bridge coupled vibration under seismic load was more and more paid attention.

So far, the dynamic response analysis of vehicle-bridge system under earthquake action was carried out by many scholars at home and abroad, and had made great progress. Yang and Wu et al studied the stability of the train which had been running on the bridge when the earthquake occurred by establishing the three-dimensional vehicle-bridge model, considering the impact of the rail system. And the impact of vertical ground motions were analyzed finally[3]; China's Taiwan Fang Zhilong made some train running safety research and analysis under earthquake through simplifying vehicle 12 degrees of freedom, and the dynamic response analysis of vehicle-bridge system was made finally[4]. Xia He, which come from Beijing Jiaotong University, studied the train running safety and dynamic response of bridge when the trains run through arch, multi-span girders, prestressed concrete continuous beam bridge under earthquake loads [5-7].Zhang Zhiyong, who works in central south university, carried out the research of vehicle bridge coupling vibration under earthquake action[8]. In addition, the scholars in railway academy of sciences, Tianjin university and other colleges and universities also studied the issue $[9,10]$.

The above researches paid more attention to the dynamic response of bridge and train system under earthquake load, and seismic waves were mostly consistent input, however, the ground motion was a complicated time-spatial processes when the actual earthquake occured. 
Bridge was regarded as a multi-span narrow structure, each support point fluctuations was great different due to topographic effect, traveling wave effect and coherence effects, so the multipoint excitation seismic wave input was more reasonable to study the problem of seismic wave input mode. Meanwhile, between the vehicle-bridge system and the ground existed energy exchange, it was necessary to consider SSI.

In this paper, on the basis of the previous scholars interrelated research and multi-source viscousspring superposition artificial boundary theory, the finite element simplified calculation model involved in foundation, soil foundation and bridge was built by the finite element software ABAQUS[11] user subroutines. The influence of different seismic wave incident angle, the train speed and SSI on the vertical dynamic response of vehicle-bridge system .was discussed.

\section{Establish Vehicle-bridge-foundation Overall Calculational Model under Earthquake Load}

\section{Construct Vehicle Model}

The vehicle model adopted Japanese Shinkansen 300 Series wheel-rail high-speed trains (abbreviated as JR300), utilized ABAQUS software in the simulation, and the body of the vehicle was made the following simplification: for the train system parts, vehicle body, bogies and wheels mass were represented by a single particle mass, consider the stiffness and damping coefficient of the spring in the primary and secondary suspension system, and did not take into account the high vibration frequency of the internal parts of the body and the vehicle itself; the half of the length between vehicle centers was set as $8.75 \mathrm{~m}$, the half of the inflexible wheel base was set as $1.25 \mathrm{~m}$, body mass $\mathrm{ms}$ is $41750 \mathrm{~kg}$, bogies mass $\mathrm{mt}$ is $3040 \mathrm{~kg}$, wheels mass $\mathrm{mw}$ is $890 \mathrm{~kg}$, secondary suspension stiffness $\mathrm{K} 2$ is $2.65 \mathrm{x} 105 \mathrm{~N} / \mathrm{m}$ and suspension damping C2 is $4.51 \times 104 \mathrm{~N} \cdot \mathrm{s} / \mathrm{m} 4$, primary suspension stiffness $\mathrm{K} 2$ is $1.18 \times 106 \mathrm{~N} / \mathrm{m}$ and suspension damping $\mathrm{C} 2$ is $3.92 \times 104 \mathrm{~N} \cdot \mathrm{s} / \mathrm{m} 4$. Each part of the body structure and the parameters were shown in Figure 1.

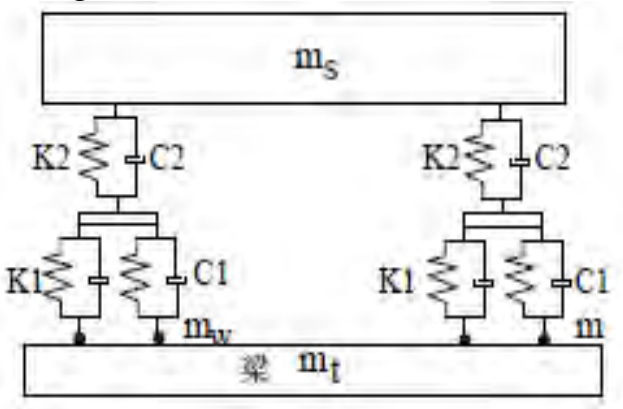

Fig. 1 The Structural Drawing of JR300 Track

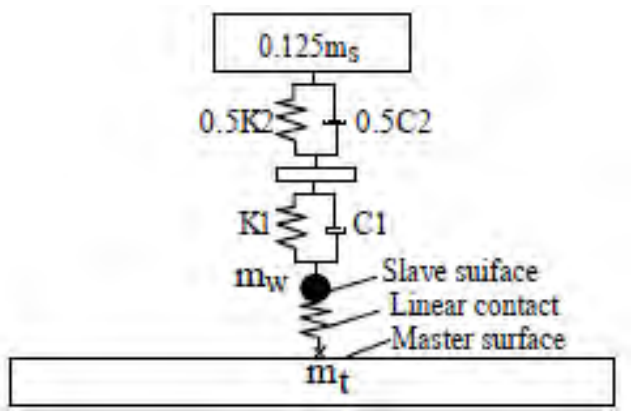

Fig. 2 The Model of Vehicle-track Contact

\section{Simulation of Wheel-rail Contact}

Assuming that the vehicle wheel was a quality node and the bridge was set to be a beam element in computing. Only considering the positive interaction behavior between the two contact surfaces, through the linear spring of the wheel-rail contact whose stiffness values was $8.0 \times 108 \mathrm{~N} / \mathrm{m}$ to perform the coupled simulation of the wheel-rail contact.

\section{The Establishment of Vehicle - bridge Dynamic System Considering Multi-support Excitation and Soil-structure Dynamic Interaction}

The seismic waves adopted the method of ground motion input that based on the multi-source viscous-spring artificial boundary. Based on this method, the overall dynamic response calculation model of the vehicle-bridge-foundation system, including the foundation soil, also could simultaneously consider the factors of the soil- structure interaction,terrain effect,the speed was built, shown in Figure 3. The bridge was 4-span continuous bridge, the span combination of main bridge was $40 \mathrm{~m}+60 \mathrm{x} 2 \mathrm{~m}+40 \mathrm{~m}$, the height of the bridge pier was $20 \mathrm{~m}$. Beam parameters was shown in Table1, the bridge was located in the concave valley area, foundation finite field ranged from $100 \mathrm{~m} \times 400 \mathrm{~m}$, foundation soil parameters 
was shown in Table 3 , all the infrastructure were made of $2 \times 3$ pile group with a rigid cap, the cap size was $3.0 \mathrm{mx} 7.0 \mathrm{~m}$, pile length was $25 \mathrm{~m}$, the far left support was a fixed support, and the remaining supports were the free supports; calculation parameters of pile group were shown in Table 2. In ABAQUS, spring damper unit was applied to achieve viscous-spring artificial boundary, a for multi-source viscous-spring artificial boundary, the boundary viscous-spring coefficient was not the same for each node, the loading force and loading time of each point when input the fluctuation were not in common, so program subroutine for achieve dynamic viscous-spring artificial boundary load automatically and accurately and load application in the calculation, it could be easily achieved the input of ground motion[12].

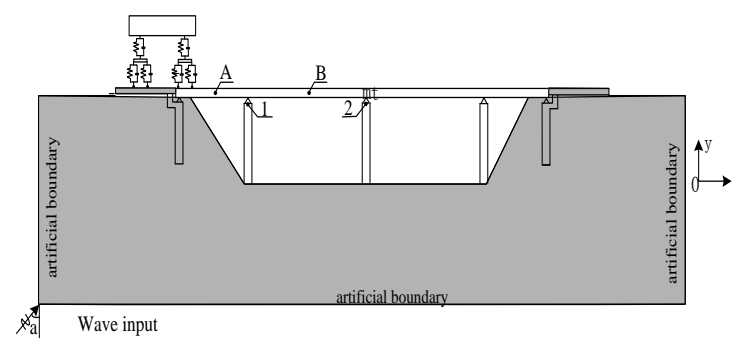

Fig. 3 Calculational Model Vehicle-track System under Earthquake

Tab.1 Soil Parameter

\begin{tabular}{ccccc}
\hline parameter & $\rho\left(\mathrm{Kg} / \mathrm{m}^{3}\right)+\mathrm{Vs}(\mathrm{m} / \mathrm{s})$ & $\nu$ & $\mathrm{G}(\mathrm{MPa})$ \\
\hline foundation soil & 1800 & 648.4 & 0.30 & 35.5 \\
\hline
\end{tabular}

Tab.2 Bridge Section and Material Properties

\begin{tabular}{cccccc}
\hline parameter & $\mathrm{A}$ & $\mathrm{Iy}\left(\mathrm{m}^{4}\right)$ & $\rho\left(\mathrm{Kg} / \mathrm{m}^{3}\right)$ & $E\left(\mathrm{kN} / \mathrm{m}^{2}\right)$ & $V$ \\
& $\left(\mathrm{~m}^{2}\right)$ & & & & \\
\hline girder & 26.1 & 10.3 & 2450 & $2.5 \mathrm{e} 7$ & 0.20 \\
pier & 12.0 & 4.67 & 2300 & $2 \mathrm{e} 8$ & 0.16 \\
\hline
\end{tabular}

\section{The Dynamic Response of the Vehicle-bridge Under Earthquake Action}

The dynamic response of the vehicle-bridge system was simulated separately when seismic waves was inputted at different incident angles, and the train speed were taken $100 \mathrm{~km} / \mathrm{h}, 150 \mathrm{~km} / \mathrm{h}, 200 \mathrm{~km} / \mathrm{h}$, $250 \mathrm{~km} / \mathrm{h}, 300 \mathrm{~km} / \mathrm{h}$. Seismic waves adopted EI Centro (N-S) wave, seismic wave incident angle was $0^{\circ}$, $15^{\circ}$ and $30^{\circ}$ separately.The dynamic response of the bridge was calculated under different wave oblique incident angle and different train speed.

\section{The Calculation Results Analysis}

\section{Analysis of Seismic Wave Incident Angle Effect on Bridge Dynamic Response}

Seismic wave was the EI-Centro Centro wave in the N-S direction. When the seismic wave was inputted, equivalent force on the Boundary point was inputted according to the SV wave oblique incidence. The earthquake happened before was the train into the bridge. Under different Angle of incidence with $0^{\circ}, 15^{\circ}$ and $30^{\circ}$ respectively, When the speed was $100 \mathrm{~km} / \mathrm{h}$, the comparison of dynamic response time history for each bridge reference point was shown in Figure 4 5.

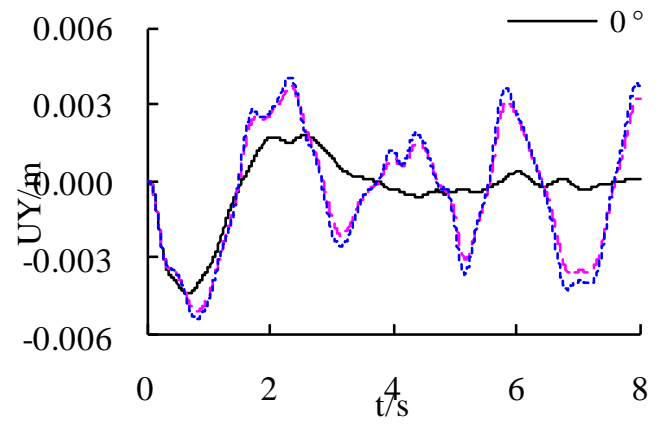

(a)Mid-span Vertical Displacement at First Span

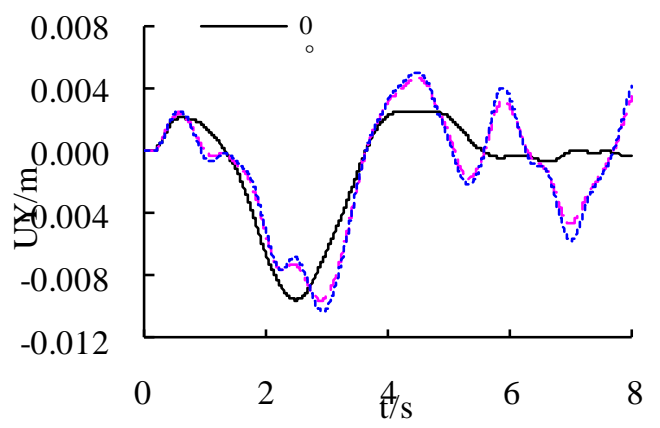

(b)Mid-span Vertical Displacement at Second Span

Fig. 4 Comparison of Vertical Displacement Time-history Curves at Different Incident Degree 


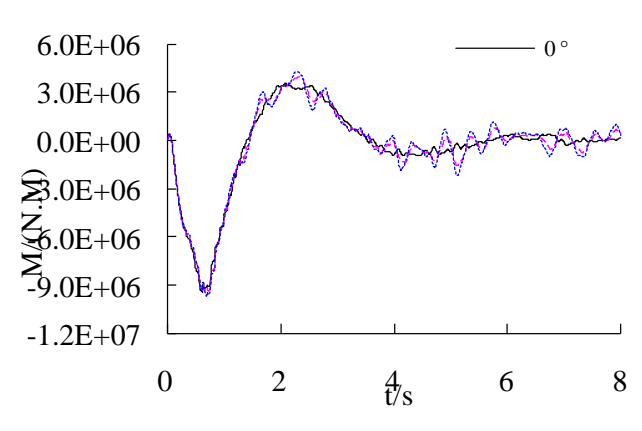

(a)Mid-span bending moment at first span



(b)Span-end bending moment at first span

Fig. 5 Comparison of Moment TIme-history Curves at Different Incident Degree

From the figure 4 5, seismic wave incident angle had a significant effect on the dynamic response of the bridge, with the incident angle increasing, the vertical displacement, velocity and acceleration of mid-span were also constantly increasing. The increasing effect from $0^{\circ}$ to $15^{\circ}$ was most evident. When the speed was $100 \mathrm{~km} / \mathrm{h}$, the maximum of vertical displacement was increased to $13.5 \%$. When the wave incident degree was greater than $15^{\circ}$, incident degree was not obvious influence on the dynamic response of the bridge. Between $0^{\circ}$ and $30^{\circ}$, the bending moment of reference point cross-section had increased with the increase of incident degree slightly, but the overall impact was smaller.

\section{Analysis of the Speed under Seismic Wave Oblique Incidence Effect on Bridge Dynamic Re- sponse}

When seismic waves was inputted at $30^{\circ}$, the vertical displacement, velocity, acceleration and maximum bending moment of reference points a, b of bridge varied with the speed shown in Figure 6 .

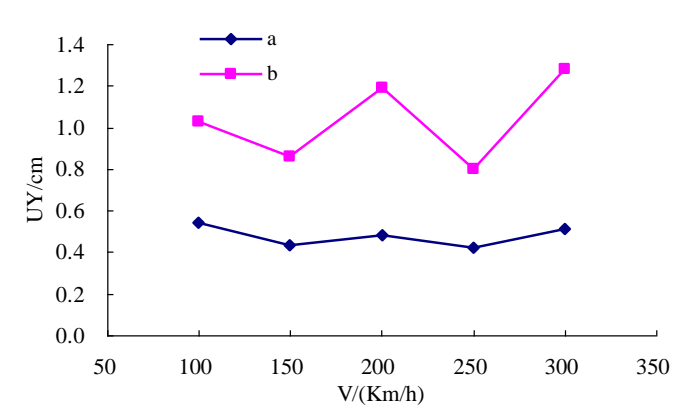

(a)Peak vertical displacement



(c)Peak vertical Acceleration



(b)Peak vertical velocity

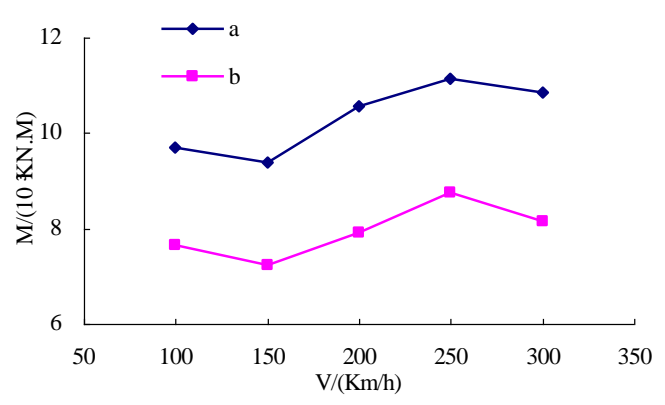

(d)Peak moment

Fig. 6 Comparison of Peak Moment and Displacement at Different Train Speed

Because the effect of earthquake excitation and vehicle loads at the same time, the dynamic response of a bridge under seismic load and no-seismic load was different along with the change of train speed. Response parameter of bridge always ignoring seismic load increased with the speed of the train operation. From Figure 8, the dynamic response of bridge structure caused by seismic load was not always 
increasing with train speed increasing. The different response parameters of bridges under the earthquake and train load could reach maximum under a certain speed.

\section{Analysis of Soil-structure Dynamic Interaction Effect on Bridge Dynamic Response}

When seismic waves was incident at $15^{\circ}$ and speed was $200 \mathrm{~km} / \mathrm{h}$, under considering SSI and ignoring SSI method, each reference point dynamic response of bridges was shown in figure 7.

The SSI had greater influence on the vertical displacement and bending moment of reference section. Ignoring the SSI, the vertical displacement solved by integral method increased obviously, mid-span bending moment decreased, but the bending moment at pier top increased.

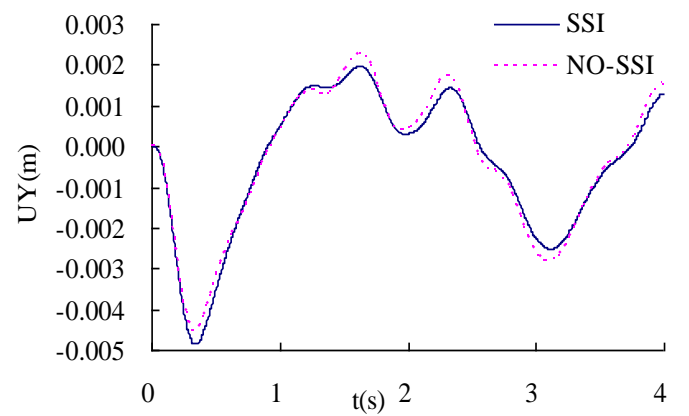

(a)Mid-span vertical displacement at first span

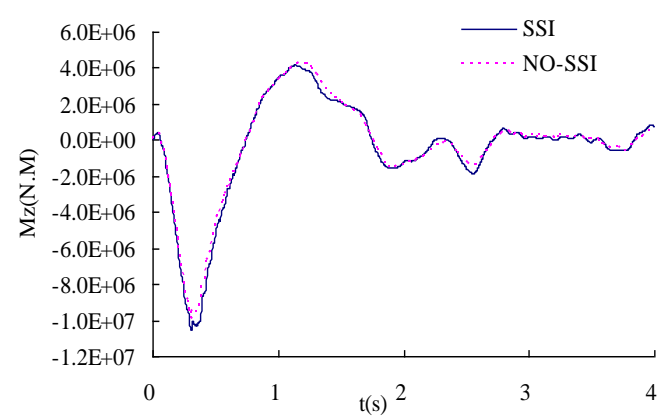

(c)Mid-span bending moment at first span

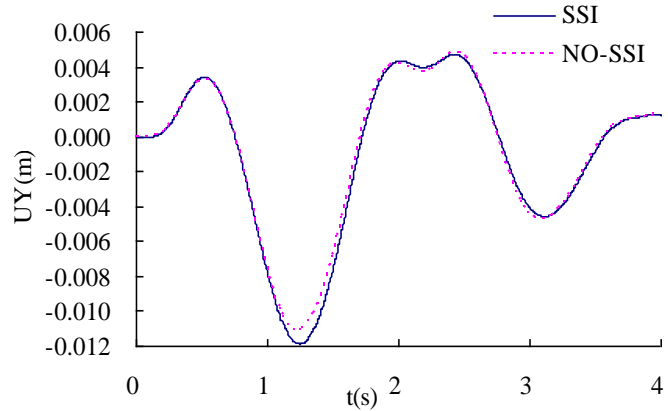

(b)Mid-span vertical displacement at second span



(d)Span-end bending moment at first span

Fig.7 Displacement and Moment Time-history Curves with and without Considering SSI

\section{Summary}

(1) The incident degree of seismic wave had a significant effect on the dynamic response of the bridge, with the incident angle increasing, the vertical displacement, velocity and acceleration of mid-span increased constantly. The increasing effect from $0^{\circ}$ to $15^{\circ}$ was most evident. The impact of after the incident degree on the dynamic response of the bridge was not obvious. Between $0^{\circ}$ and $30^{\circ}$, the bending moment of reference point cross-section had increased with the increase of incident degree slightly, but the overall impact was smaller.

(2) Under the earthquake action, the train speed impacting on the dynamic response of Bridges was relatively small. The dynamic response of bridge structure was not always increased with the train speed increasing, but reached the maximum at a certain speed.

(3) The soil-structure dynamic interaction had greater effect on dynamic response of the bridge. No considering SSI, the vertical displacement and bending moment at pier top increased significantly, and mid-span bending moment was reduced.

\section{Acknowledgement}

This research was financially supported by the Specialized Research Fund for the Doctoral Program of Higher Education (20134101120009) and the Key Programs of Education Department of Henan Province(14A560014). 


\section{References}

[1]Liu H X. Research of disasters in Tangshan Earthquake(III). Beijing: Seismological Press, 1986.

[2]Han Y. Dynamic Responses of High-Speed Railway Bridges and Running Safety of Vehicles during Earthquakes [D].Beijing:Ph. D. Dissertation of Beijing jiao tong university, 2005.

[3]Yang Y B, Wu Y S. Dynamic stability of trains moving over bridges shaken by earthquakes [J]. Journal of Sound and Vibration, 2002, 258(1): 65-94.

[4]Fang Zh L. Research of Running Safety of Single Vehicles When Crossing the Railway Bridge During the Earthquakes [D]. Taiwan: the Research institution of Civil Engineering in center university, 2005.

[5]Zhang N, Xia H. Influence of earthquakes on running safety of vehicles on muti-span girders bridge [J].World information on earthquake engineering. 2001,17(4):93-99.

[6]Han Y, Xia H, Guo W W. Dynamic Response of Cable-Stayed Bridge to Running Trains and Earthquakes[J]. Engineering Mechanics, 2006, 23(1):93-98.

[7]Han Y, Xia H, Zhang N. Dynamic Response Analysis of Train-Bridge System under Non-Uniform Seismic Excitations [J]. China Railway Science, 2006, 27(5):47-53.

[8]Zhang Zh Y. Study on vehicle bridge coupling vibration under the action of earthquake on high speed railway continuous steel truss bridge [D]. Changsha: Master's thesis of Central South University, 2008.

[9]Gao M M. Research of High speed railway train track bridge coupling vibration and train [D]. Beijing: Doctoral Dissertation of China Academy of Railway Sciences. 2001.

[10]Huang J. Coupled Vibration Analysis of Train-Bridge System and Its Environmental Vibration Effect On Surrounding Buildings [D].Tianjin: Ph. D. Dissertation of Tianjin university, 2006.

[11]Zhuang ZH. The Finite Element software ABAQUS tutorial [M]. Beijing: Tsinghua University press, 1999.

[12]Gao X J. Seismic Response Analysis of Long-span Bridge Considering Earthquake and Vertical Trainloads [D].Beijing: Ph. D. Dissertation of Beijing Jiaotong University, 2011. 